Presented at the Particle Accelerator

Conf., Chicago, Ill., March 1-3, 1971
UCRL-20179

Preprint

Cont- $710308--21$

PCM TELEMETRY SYSTEM FOR 3-MV SUPERHILAC INJECTOR

L. L. Reginato, N. J. Dobeck, and B. H. Smith

February 1971

AEC Contract No. W-7405-eng-48
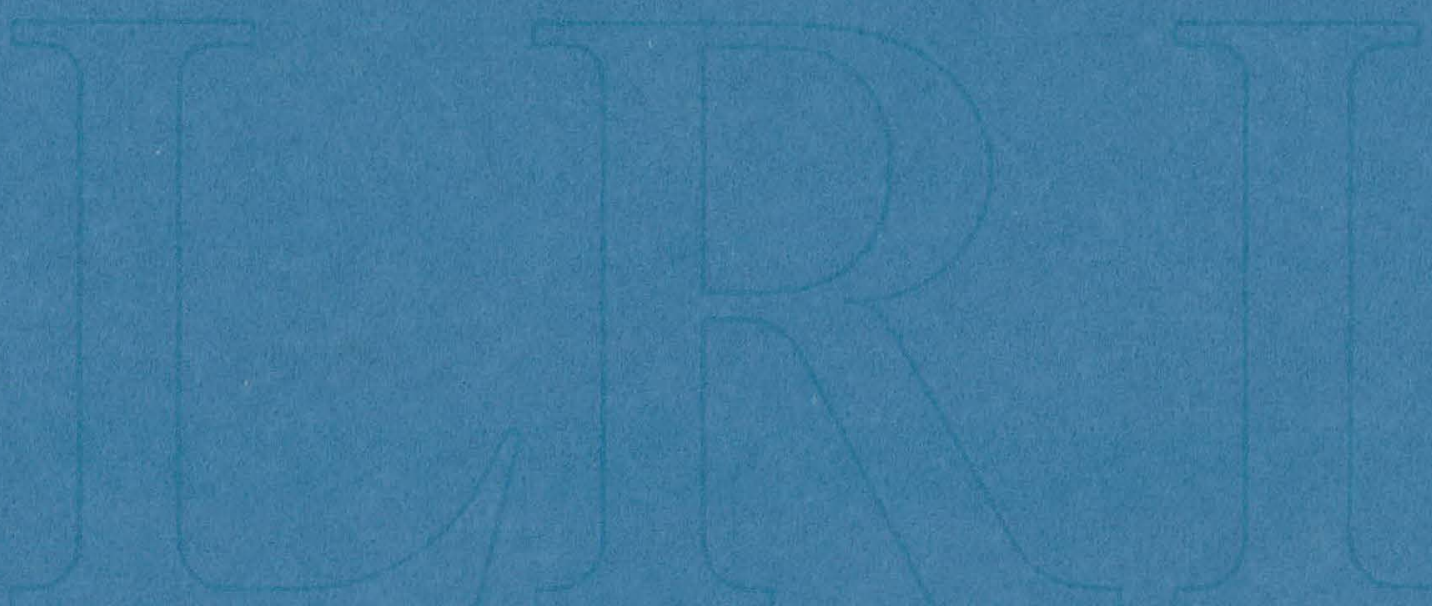


\section{DISCLAIMER}

This report was prepared as an account of work sponsored by an agency of the United States Government. Neither the United States Government nor any agency Thereof, nor any of their employees, makes any warranty, express or implied, or assumes any legal liability or responsibility for the accuracy, completeness, or usefulness of any information, apparatus, product, or process disclosed, or represents that its use would not infringe privately owned rights. Reference herein to any specific commercial product, process, or service by trade name, trademark, manufacturer, or otherwise does not necessarily constitute or imply its endorsement, recommendation, or favoring by the United States Government or any agency thereof. The views and opinions of authors expressed herein do not necessarily state or reflect those of the United States Government or any agency thereof. 


\section{DISCLAIMER}

Portions of this document may be illegible in electronic image products. Images are produced from the best available original document. 


\title{
PCM TELEMETRY SYSTEM FOR 3-MV SUPERHILAC INJECTOR *
}

\author{
L. L. Reginato, N. J. Dobeck, and B. H. Smith \\ Lawrence Radiation Laboratory, University of California \\ Berkeley, California 94720
}

\section{Introduction}

A time-division multiplex communications system using pulse code modulation (PCM) has been built for the new 3-MV SuperHilac injector. Transmission between the high-voltage terminal and ground uses light beams generated by light-emitting diodes and is received by photodiodes. With each accelerator pulse a sequence of 384 time slots is transmitted--each defined by a clock pulse transmitted over an adjacent light beam. Binary information is then conveyed by the presence or absence of pulses in the appropriate time slots. This system can handle, in either direction, 16 parallel analog input channels which are encoded into 16 12-bit binary coded decimal (BCD) serial words and 192 parallel "ON-OFF" input channels which are also encoded into 1612 -bit serial words. Thus a serial transmission in either direction consists of 32 12 -bit words.

\section{Optical Modulator}

The optical modulator consists of a pulsed lightemitting diode (LED), Monsanto ME2A, emitting infrared light at $9000 \AA$. The light receiver is an E. G. \&G. SGD-100 which has a response peak at $9000 \AA$. Pulse width is $1 \mu \mathrm{sec}$ and the repetition rate is $50 \mathrm{kHz}$. Figure 1 shows a photo and schematic of the sender and receiver. The honeycomb grating in front of the lens shields the receiver from stray light generated by sparks.

\section{General Description}

Figure 2 shows the basic elements of one PCM data path, from terminal to ground end. One optical link is used to send clock information from the ground end to the terminal so that the data transmitters and receivers will be synchronized. The second optical link sends PCM data up to the terminal, while a third optical link sends PCM data from terminal to ground. In addition to the PCM data channels, there are also two analog optical channels which continuously monitor arc current and extractor potential in the ion source.

\section{System Programmer Description}

Referring to Fig. 2, the ground-end clock is gated on by the accelerator on pulse and is internally gated off after $32 \times 12$ clock pulses. This means that data will be sampled at the SuperHilac pulse rate, which is about 30 pulses per second.

In addition to shifting information in and out of the serial data channels, the $50-\mathrm{kHz}$ clock also drives a modulus-12 counter which puts out 1 pulse for every 12 input pulses. This output pulse then drives a 1 of 32 decoder which sequentially specifies which 12 -bit data word is to be proressed. After processing a $32-$ word pulse train the system programmer produces a signal to reset the counters.

\section{Data Input and Output}

The 16 analog inputs are sampled by a 16-channel MOSFET multiplexer driven by outputs 1 through 16 of the 1 of 32 decoder. The multiplexer output feeds a successive approximation analog to digital converter (ADC) which produces a 12 -bit BCD encoded serial output. Input information is stored in 16 12-bit registers, which shift their data out as they are in turn selected by outputs 17 through 32 of the 1 of 32 decoder. The data outputs of the ADC and switch registers are "OR"ed onto a single serial channel. After being received on the other end, the data are shifted into 32 12 -bit holding registers. Since the ground and terminal ends are synchronized, the received, or output, data have the same word and bit location as the transmitted data. The first 16 holding registers are used to drive nixie readouts while holding registers 17 through 32 drive relay buffers. These relays not only control the on-off functions but also operate motordriven helipots which control pulse width and amplitude levels.

\section{Circuit Protection}

Special precautions were taken in the terminal portion of the telemetry to protect the delicate integrated circuits from 3-MV spark-induced transients. These precautions include double shielding, input and output isolation with either photon decouplers for analog or fast pulsed data, or relays for switch data. All low-frequency inputs and outputs have rf filters. Lines that cannot have RC filtering because of frequency requirements have fast transient suppressors instead.

\section{Conclusion}

The availability of suitable integrated circuits has made it possible to develop a PCM telemetry system for communication between the high-voltage terminal and ground. Because PCM exchanges bandwidth and signal-to-noise ratio exponentially, rather than linearly, it is possible to more closely approach Shannon's information capacity limit than with other types of modulation. This exhibits itself in the present case by providing 16 analog channels with a resolution of one part in 4096 and 192 "ON-OFF" channels. There is enough time between accelerator pulses to expand the number of channels by a factor of 4 if it ever becomes necessary.

\footnotetext{
*Work done under the auspices of the U. S. Atomic Energy Commission.

This report was prepared as an account of work sponsored by the United States Government. Neither the United States nor the United States Atomic Energy Commission, nor any of their employees, nor any of their contractors, subcontractors, or their employees, makes any warranty, express or implied, or assumes any legal liability or responsibility for the accuracy, completeness or usefulness of any information, apparatus, product or process disclosed, or represents that its use would not infringe privately owned rights. 

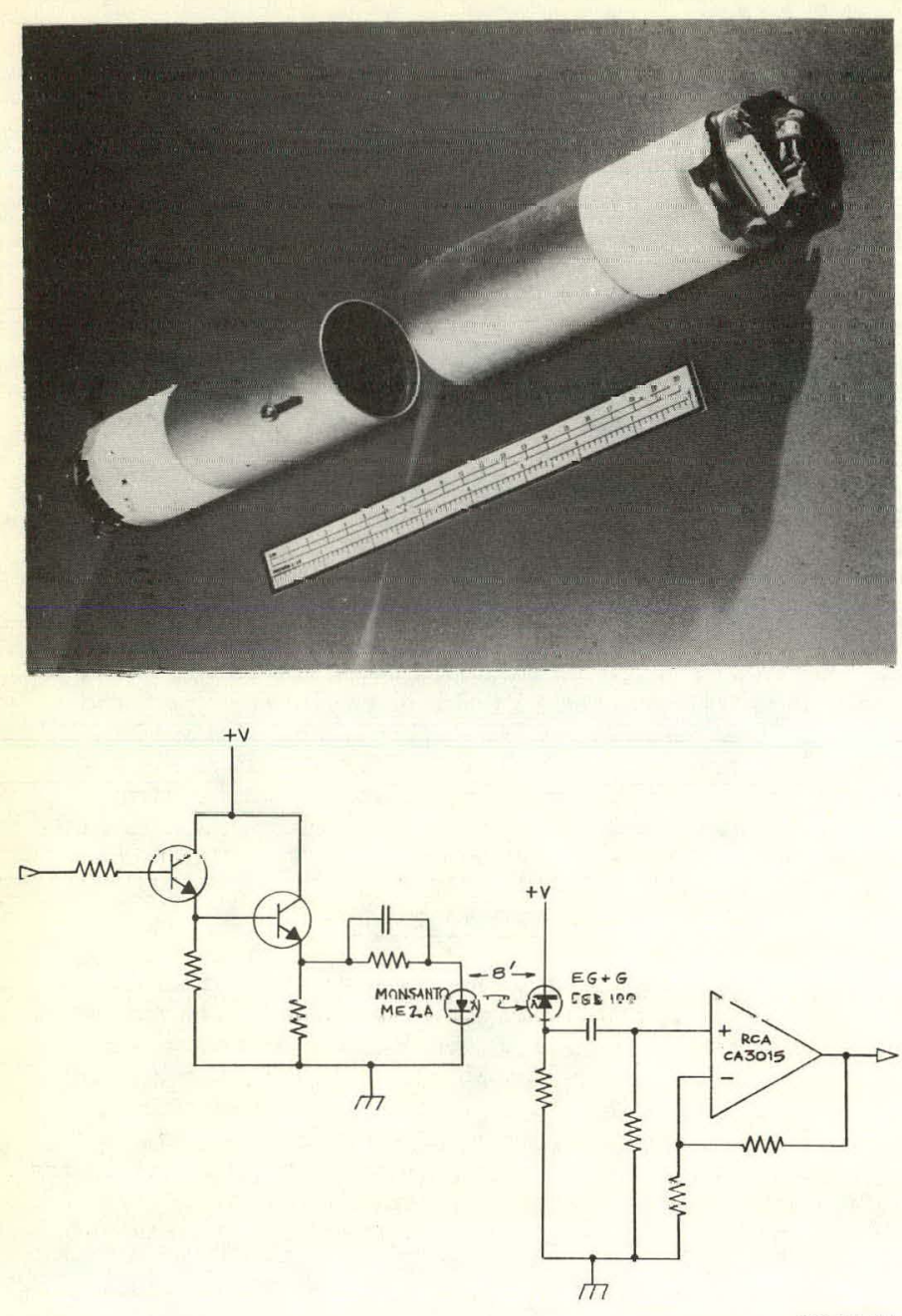

XBL $712-244$

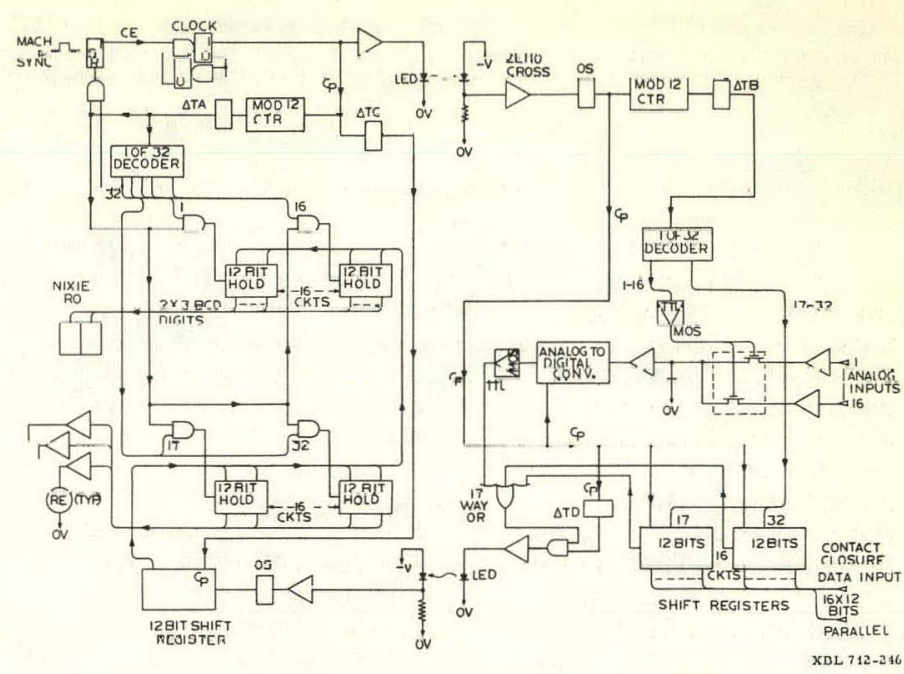

Fig. 2. Basic elements of one PCM data path, from terminal to ground end.
Fig. 1. Photograph and schematic of sender and recelver. 


\section{LEGAL NOTICE}

This report was prepared as an account of work sponsored by the United States Government. Neither the United States nor the United States Atomic Energy Commission, nor any of their employees, nor any of their contractors, subcontractors, or their employees, makes any warranty, express or implied, or assumes any legal liability or responsibility for the accuracy, completeness or usefulness of any information, apparatus, product or process disclosed, or represents that its use would not infringe privately owned rights. 
TECHNICAL INFORMATION DIVISION

LAWRENCE RADIATION LABORATORY UNIVERSITY OF CALIFORNIA BERKELEY, CALIFORNIA 94720 